\title{
Sonho de uma noite de verão: do texto de Shakespeare à opera de Benjamin Britten
}

\author{
Anna Stegh Camati
}

\section{Introdução}

A ópera, assim como a opereta, o musical, o music hall e o cabaré, é um gênero de teatro musical ${ }^{1}$ complexo que se desdobra em diversos subgêneros, como a ópera séria, a ópera bufa, a ópera balada, a ópera de câmara, entre outros. Trata-se de uma manifestação artística plurimidiática que, bebendo de fontes variadas como a literatura, a música, o teatro, a dança e as artes plásticas, propõe estéticas híbridas. Desde a sua incepção na Itália do século XVI até o final do século XIX, quando o público lotava as suntuosas salas de espetáculo dos edifícios teatrais, a ópera foi cultuada, principalmente pelas elites. No início do século XX, com o advento do modernismo, as manifestações do gênero perderam muito de seu apelo. Porém, com a crise da modernidade, o interesse por elas voltou a crescer, sendo que, na década de 1990, o gênero popularizou-se novamente com o lançamento de inúmeras gravações disponíveis em VHS e, mais tarde em DVD, de encenações e adaptações operísticas regidas por maestros de renome.

Como todas as outras formas de arte, a ópera sofreu variações através dos tempos, sendo que o repertório romântico tornou-se a modalidade dominante no século XIX. A ópera romântica privilegiou peças de teatro e romances trágicos, o que nos leva a pensar não ser surpresa alguma que as peças de Shakespeare atraíram a atenção de grandes compositores. Diversos textos do dramaturgo foram utilizados como fontes para a criação de

\footnotetext{
${ }^{1}$ De acordo com Béatrice Picon-Vallin (2008, p. 20), “A noção de teatro musical é fluída: em sua acepção mais ampla, é utilizada para designar todo gênero artístico que mistura elementos teatrais e musicais, não importando qual seja a proporção de cada um desses dois componentes [...]. Ela designa, portanto, todas as produções em que se tenta integrar música, texto e elementos visuais".
} 
óperas famosas no século XIX, com destaque para Otello (1816), de Gioachino Rossini (1792-1868); Macbeth (1847), Othello (1887) e Falstaff (1893), de Giuseppe Verdi (1813-1901); Béatrice et Bénédict (1862), de Hector Berlioz (1803-1869); Roméo et Juliette (1867), de Charles Gounod (1818-1893) e, no século XX, os principais destaques foram a ópera de câmara Sonho de uma noite de verão (1960), de Benjamin Britten (1913-1976), e Lear (1978), do compositor alemão Aribert Reimann (n. 1936).

Ao longo dos séculos, houve inúmeras adaptações musicais do texto shakespeariano Sonho de uma noite de verão (1595-1596) por tratar-se de uma peça na qual a música e a dança não são apenas efeitos embelezadores, mas elementos essenciais ao lado dos ritmos e cadências do lirismo shakespeariano. Na seção "Lyricism, Music and Dance", que integra a introdução da edição Arden Shakespeare de Sonho de uma noite de verão, Harold Brooks (2003, p. cxxii) argumenta: "Quando o verso falado é tão variado em suas formas, e tão frequentemente em tom lírico, a distância do diálogo para a música não é grande. E as canções e danças não são menos parte integrante do drama do que os discursos verbais". ${ }^{2}$

Em Shakespeare and Music: Afterlives and Borrowings, Julie Sanders (2007, p. 29) ressalta que "Shakespeare estabeleceu seu próprio precedente no teatro". Ao inserir a música e a dança como parte integrante de seu projeto dramático gerou o impulso para adaptações operísticas ou semioperísticas do Sonho desde o final do século XVII e ao longo do século XVIII. Assim como Brooks, Sanders acredita que os elementos musicais nos textos shakespearianos não exercem apenas a função de pontuação dramática ou realce emocional, mas estão integrados no projeto dramático do dramaturgo. Não é surpresa, portanto, que o impulso de adaptar o Sonho à forma musical tenha permanecido forte desde o final dos século XVII, quando as estratégias cênicas emprestadas das mascaradas (masques) e entretenimentos das cortes dos Stuarts foram utilizadas como elementos formativos (SANDERS, 2007).

As inúmeras adaptações musicais do Sonho, que começaram a surgir logo após a estreia da peça de Shakespeare, com músicas, danças e balés

\footnotetext{
2 Todas as traduções de citações extraídas de obras ainda não publicadas em português são de minha autoria e responsabilidade.
} 
adicionais, eram a tal ponto frequentes à época de modo a causar uma diluição da "linha divisória entre o Shakespeare operístico e o teatral" (SANDERS, 2007, p. 32). No teatro da Restauração, William Davenant (1606-1668), Thomas Killigrew (1612-1683) e Nahum Tate (1652-1715) adaptaram os textos de Shakespeare para atender aos novos gostos do público à época. Eles adicionaram novos elementos não incluídos nas peças shakespearianas, produzindo adaptações suplementadas "não somente com novos diálogos, cenas e personagens, mas também com novas oportunidades para a performance musical" (SANDERS, 2007, p. 31).

As versões operísticas e semi-operísticas criadas durante a Restauração e no período seguinte, como a semiópera barroca The Fairy Queen (1692), de Henry Purcell (1659-1695), e The Fairies (1755), de David Garrick (1717-1779), influenciaram diversas adaptações musicais posteriores. Sanders destaca que os aspectos operísticos da encenação de The Fairy Queen são todos concebidos como

[...] entretenimentos e mascaradas encenadas pelas fadas para os diferentes espectadores dentro da peça, incluindo Bottom e, no último ato, temos a mascarada de Oberon para Teseu e sua comitiva - substituindo assim a peça dos artesãos em termos estruturais e oferecendo um clímax muito mais mágico e exótico, e uma recusa à comédia no final. (SANDERS, 2007, p. 127)

A ópera de câmara Sonho de uma noite de verão, em três atos, foi um trabalho encomendado a Britten ${ }^{3}$ pelos organizadores do Festival de Glyndebourne, para a reabertura do luxuoso Jubilee Hall em 1960. Como não havia tempo suficiente para conceber um libreto 'original', o compositor britânico e seu companheiro Peter Pears (1910-1986) basearam a escrita do libreto no texto homônimo de Shakespeare. O presente ensaio objetiva refletir sobre o processo de criação dessa ópera, desde o libreto de Britten/Pears, passando por algumas inovações introduzidas por Britten na composição da partitura, até a performance dramática, disponível em DVD, dirigida pelo celebrado encenador e régisseur Sir Peter Hall (1930-2017), no

\footnotetext{
${ }^{3}$ A ópera Sonho de uma noite de verão, de Britten, estreou no Jubilee Hall, Aldeburgh, em 11 de junho de 1960. A estreia nos Estados Unidos foi no War Memorial Opera House, São Francisco, em 10 de outubro de 1961.
} 
Festival de Ópera de Glyndebourne em $1981 .^{4}$ A regência do espetáculo foi do maestro Bernard Haitnik (n. 1929) que conduziu a Orquestra Filarmônica de Londres na ocasião; e o cenário e os figurinos foram assinados por John Bury (1925-2000). Os diálogos intermidiáticos entre Shakespeare, Britten e Hall serão investigados à luz de considerações teóricas de influentes críticos da contemporaneidade.

\section{Considerações sobre o discurso sincrético na ópera encenada}

Segundo Claus Clüver (2006), “a ópera, enquanto modelo textual, é multimídia", uma vez que se compõe de "textos separáveis e separadamente coerentes" (p. 19). Assim, "um libreto de ópera pode ser publicado e recebido por si só, do mesmo modo que a partitura" (p. 19): aberturas são tocadas em concertos, e árias são cantadas em apresentações musicais, fora do contexto da ópera em que estão inseridas. Outrossim, a intrincada tessitura do espetáculo operístico, por situar-se na interface de múltiplas mídias, como a literatura, a música, o teatro, a dança e as artes visuais, pode ser considerada um texto mixmídia por conter "signos complexos em mídias diferentes que não alcançariam coerência e ou autossuficiência fora daquele contexto" (p. 19). Contudo, alguns críticos consideram a ópera encenada um texto intermídia devido à simultaneidade de percepção de todos os elementos compositivos no momento da recepção.

A integração de palavra e música na ópera encenada é um discurso sincrético, uma vez que se configura a partir "dois ou mais sistemas de signos e/ou mídias de uma forma tal que os aspectos visuais e/ou musicais, verbais, cinéticos e performativos de seus signos se tornam inseparáveis e indissociáveis" (CLÜVER, 2006, p. 20). De acordo com essa linha de raciocínio, Freda Chapple (2006, p. 81-88) postula que o discurso operístico, ou seja, as palavras cantadas e mediadas pela voz do performer no momento da recepção da ópera encenada, pode ser visto não como uma justaposição de música e palavra, mas como a fusão de ambas em um novo idioma. Em sua análise da ópera balada Ascenção e queda da cidade de Mahagonny (1930), de

\footnotetext{
4 Sir Peter Hall é diretor de teatro e cinema, e régisseur de ópera. Fundou e foi diretor da Royal Shakespeare Company (1960-1968); diretor do National Theatre em Londres (1973-1988); e diretor artístico do Glyndebourne Festival Opera (1984-1990).
} 
Bertolt Brecht (1898-1956), a autora utiliza o epíteto de "performer intermidiático" para o ator-cantor de ópera por emprestar sua voz para cantar a poesia musicada: ele é um mediador que funde o texto escrito ou libreto com a partitura musical, tornando-se, portanto, o principal veículo de enunciação do discurso sincrético do espetáculo operístico, uma forma intermidiática por excelência.

Esta perspectiva a respeito da impossibilidade de perceber a palavra de um lado e a música de outro durante a encenação de uma ópera é corroborada por Jorge Coli, professor de história da arte e cultura da Unicamp e crítico do jornal Folha de S. Paulo. Para ilustrar seu ponto de vista, Coli (2003) discute essa questão a partir das metalinguagens inscritas na ópera Capriccio (1942), de Richard Strauss (1864-1949), cujo subtítulo bastante sugestivo é "Uma peça conversacional sobre música". Relata que, na ópera de Strauss, as personagens principais são um poeta, um compositor e uma condessa, sendo que o amor da última é disputado pelos dois artistas que empregam os artifícios de suas respectivas artes para seduzi-la. Nesse sentido, o poeta escreve e recita um soneto e, de imediato, o rival musicaliza os versos e se empenha em cantá-los. A condessa, comovida, filosofa sobre o que acaba de ouvir:

Foi através das palavras que ele encontrou a chave para a sua música? A música estava prenhe, aguardando para cantar os versos e abraçá-los? Nossa linguagem foi sempre possuída pelo canto ou é a música que extrai seu sangue vital das palavras? Uma sustenta a outra, uma precisa da outra. Na música, as emocões clamam pela linguagem. Na palavra existe uma ânsia pela música e pelo som. (Apud COLI, 2003, p. 13-14) ${ }^{5}$

O discurso da condessa, por demais sofisticado para uma dama da sociedade, pode ser considerado como uma espécie de "canção" brechtiana que sintetiza as reflexões de Richard Strauss a respeito da inseparabilidade da palavra e da música na ópera encenada. Cabe ressaltar que os recitativos, enunciados pela condessa em Capriccio, abrem espaço para reflexões a respeito do modo de percepção do público das especificidades da ópera encenada no momento da recepção.

\footnotetext{
${ }^{5}$ Coli cita vários trechos do libreto de Clemens Krauss e Richard Strauss (sem fazer referência ao libreto), da ópera Capriccio, em tradução livre para o português, especificamente algumas falas da condessa.
} 
Na continuidade de sua meditação, a condessa destaca: “Tudo é confusão, as palavras estão cantando, a música está falando" (Apud COLI, 2003 , p. 14) e, mais adiante, quando já não consegue distinguir ela própria dos outros elementos da cena operística, ela tece as seguintes observações: "Como o amor deles está se elevando para alcançar-me, ternamente entrelaçado de versos e de música. Como posso eu rasgar esse tecido delicado? E, não sou, eu mesma, parte dessa textura" (Apud COLI, 203, p. 14). Neste momento fica evidente que a personagem tem consciência de que ela mesma é um ser construído de palavras e música, e que "o som, a palavra, o gesto, as roupagens, o cenário são os outros fios dessa trama. Um tecido vivo, uma unidade indivisível que, durante duas horas, existe de maneira intensa" (COLI, 2003, p. 14).

Com base no discurso autorreferencial da ópera Capriccio, Coli (2003, p. 18) conclui que na ópera encenada, “a música e a palavra unidas não se justapõem: elas se transformam numa outra língua", e que a interação e interseção de outras especificidades do teatro, como o trabalho de expressão facial e corporal dos atores, coreografias, bailados e a contribuição da pintura, escultura e outros recursos audiovisuais, que interferem na gênese e composição da cena operística, formam uma tessitura inseparável no momento da recepção.

\section{A ópera como a arte da adaptação por excelência}

No artigo "Adaptation and opera", Linda e Michael Hutcheon (2017) argumentam que a ópera, desde os seus primórdios, evidencia seu pendor pela adaptação. Por ser uma prática notoriamente dispendiosa, os compositores geralmente adaptam fontes confiáveis e bem-sucedidas financeiramente a fim de evitar problemas de ordem econômica e, por conta disso, privilegiam "não o novo ou o 'original', mas o testado e o experimentado" (p. 305). A própria história da formação da identidade da arte operística mostra a derivação do gênero das mais diversas fontes, como a mitologia, a tragédia grega, romances populares, peças de teatro, poemas dramáticos e muitas outras.

Todo adaptador, em um primeiro momento, é intérprete de um texto anterior e criador de um produto novo. No artigo mencionado acima, os 
teóricos canadenses propõe três etapas distintas para a análise concreta do processo de criação e produção de uma ópera, ressaltando que em cada um desses momentos todos os envolvidos são adaptadores: o libretista adapta um texto fonte para escrever o libreto, o compositor adapta o libreto ao criar a partitura, e o régisseur adapta a ambos, o libreto e a partitura, ao transpor o texto verbal e o musical para a cena. Esse modelo tripartido será utilizado no presente estudo sobre a ópera de Britten, enquanto modelo textual (libreto), composição musical (partitura) e performance dramática (encenação).

\section{O texto shakespeariano adaptado em forma de libreto}

O libretista exerce um papel extremamente difícil, porque "a adaptação como adaptação envolve, para seu público conhecedor, uma duplicação interpretativa, um movimento conceitual para frente e para trás entre a obra que conhecemos e aquela que estamos experienciando" (HUTCHEON, 2011, p. 67). Em face dessa duplicidade de visão, que envolve a memória e a experiência do espectador no momento da recepção, o libretista geralmente é acusado como culpado da simplificação do texto verbal adaptado, por realizar grandes cortes que, segundo a opinião de grande parte da audiência com conhecimento do texto-fonte, implicam em perda de qualidade. No entanto, a compressão é estritamente necessária na arte operística, tendo em vista que leva "muito mais tempo para cantar do que para recitar uma linha ou simplesmente lê-la" (HUTCHEON, 2011, p. 67).

Em relação ao libreto, escrito por Britten/Pears em 1960, o compositor, em uma carta a William Plomer, em agosto de 1959, lamentou ter sido obrigado a realizar a compressão da peça de Shakespeare para adequar o texto à cena operística:

Se eu pudesse algum dia lhe enviar os cortes \& cozimentos de Shakespeare que eu me permiti a fazer, com a ajuda de Peter, nestas últimas semanas, eu gostaria, de receber um ou dois comentários de sua parte, se você puder - um impasse fascinante, porém desolador de ter que deixar de fora tanto material maravilhoso - mas o consolo é que, se isso não tivesse 
sido feito, ela [a encenacão da ópera] duraria tanto quanto o 'Anel'. (BRITTEN, apud PLANT, 2011, p. 11) ${ }^{6}$

Nesse sentido, uma redução drástica do texto de Shakespeare foi realizada para atender as exigências da ópera: cortes de partes de cenas ou cenas inteiras, deslocamentos, paráfrase e encurtamento de falas, transformação de falas em intervenções córicas, etc. Inspirados não somente na peça de Shakespeare, mas também na semiópera barroca The Fairy Queen (1692), de Purcell, a cena de abertura é ambientada na floresta. No entanto, a primeira cena do primeiro ato do texto de Shakespeare, que se passa na corte, foi apenas parcialmente suprimida, uma vez que partes do diálogo entre Teseu e Hipólita, proferidas no palácio, no início da peça de Shakespeare, são deslocadas para a cena final antes da peça dentro da peça do terceiro ato da ópera.

A segunda cena do primeiro ato de Shakespeare, que trata da primeira reunião dos artesãos-atores, marcada para a distribuição de papéis na casa de Pedro Quina, também é deslocada para a floresta com o intuito de concentrar a ação no universo fadas. Nesse processo, são sacrificados personagens como Egeu e Filostrato, e a ameaça de morte que paira sobre Hérmia ao longo da peça de Shakespeare é suprimida. A cena na qual Teseu e Egeu encontram os amantes na floresta também é eliminada e substituída por vários duetos entre os amantes que versam sobre as dificuldades do amor, baseados em diálogos do início da peça de Shakespeare.

Ao escolher a floresta como ambientação principal, os libretistas optaram pela criação de um núcleo centralizador, um centro dinâmico determinante para a leitura da ópera. ${ }^{7}$ Assim, à maneira de Purcell, Oberon é eleito personagem principal e a ligação homoerótica entre Oberon e Puck constitui o relacionamento central da ópera. Há uma mudança de ênfase no sentido de privilegiar a noite e seus mistérios, pois as cenas das fadas ocupam o primeiro plano.

\footnotetext{
${ }^{6}$ Na carta a Plomer, escrita em 24 de agosto de 1959, Britten se refere ao O anel dos Nibelungo, um ciclo de quatro óperas épicas do compositor alemão Richard Wagner.

7 Esse processo da escolha de um núcleo, denominado de vetorização por Patrice Pavis (2003, p. 117), é definida pelo teórico francês como "o primeiro impulso de uma narrativa, ou de uma cronologia entre diversas partes da obra cênica, o percurso do sentido pela floresta de signos, a ordenação da representação".
} 


\section{Do libreto à partitura: a linguagem musical da ópera criada por Britten}

A segunda etapa do processo criativo de uma ópera consiste na tradução do material textual em linguagem musical, ou seja, a narrativa verbal do libreto é transformada pelos compositores em música vocal - árias, duetos e coros - música instrumental e recitativos. No entanto, não se trata de música 'absoluta'; a composição operística é sempre música adaptada ao texto. Nesse sentido,

[...] sempre haverá uma dimensão extra-musical porque ela é escrita para dar voz, literalmente, a um texto dramático em palavras. Assim, há uma linha vocal e outra de música orquestral, e a relação entre essas duas partes pode ser de duplicação, ênfase, ironia ou contradição. As passagens orquestrais que não se relacionam às palavras também apresentam associações extra-musicais a partir do seu contexto dentro da ópera, mas, além disso, elas também acumulam significado à medida em que a ópera se desenrola. A forma e a função de todas essas modalidades de música operística é variável, dependendo de tempos e contextos históricos específicos. (HUTCHEON, 2017, p. 312)

Em Sonho, Britten empreende uma reinterpretação radical da ópera clássica romântica, optando por inúmeras inovações e uma multiplicidade de diferentes estilos musicais: Puck, por exemplo, desempenha um papel falado ao invés de cantado; o canto de Titânia tem proximidade com os castrati de Händel do século XVIII; e a escolha de Alfred Deller, um contratenor de qualidades excepcionais na performance de música barroca, para incarnar Oberon, o principal papel masculino, é completamente inusitada.

Em seus comentários críticos sobre seu processo de criação de partituras, Britten destaca:

Escrever uma ópera é muito diferente de escrever canções individuais: a ópera efetivamente inclui canções, mas ao mesmo tempo é constituída de muitas outras formas musicais e de uma configuração dramática geral. $\mathrm{Na}$ minha experiência, esta última é a mais importante. Com Sonho de uma noite de verão, bem como com outras óperas, primeiro procuro definir a concepção musical como um todo. Eu idealizei a obra sem definir nenhuma nota. Eu poderia ter descrito toda paisagem musical, sem tocar uma única nota. (BRITTEN, 2011, p. 57) 
O compositor também fala de seu fascínio pelo Sonho de Shakespeare. Para ele a peça tem especial apelo do ponto de vista operístico por apresentar personagens de três universos diferentes - os amantes, os rústicos e as fadas - que se integram e se misturam. Britten (2011, p. 55) revela ter utilizado "diferentes texturas e 'coloraturas' orquestrais para cada um dos universos". Assim como Shakespeare, que utiliza o verso branco para as falas dos amantes, versos rimados em metrificações diversas para as fadas, e prosa para os rústicos artesãos, o compositor cria variações musicais para os diferentes universos sociais. Além disso, seleciona instrumentos musicais diferenciados para cada um desses microcosmos: harpas e instrumentos de percussão predominam no reino das fadas; instrumentos de cordas e de sopro embalam as discussões dos amantes; e instrumentos de sopro de madeira e metais pontuam as cenas dos artesãos.

Britten presta homenagem a outros compositores que criaram versões musicais do Sonho: há várias referências à overture (1826) e à música incidental (1842) composta por Felix Mendelssohn (1809-1847), e a famosa ária de Oberon, intitulada "I know a bank", é inspirada pela música "Sweeter than roses", da composição semi-operística The Fairy Queen, de Purcell. Além disso, a peça dentro da peça é um pastiche de convenções operísticas que remetem a várias óperas italianas do século XIX: Píramo, por exemplo, entra em cena ao som de "Miserere", da ópera La Traviata (1853), de Verdi; e o lamento de Tisbe, quando se dá conta que Píramo está morto, é uma paródia brilhante de um trecho da ópera Lucia di Lammermoor (1835), de Donizetti (SANDERS, 2007).

\section{Do libreto e partitura à concretização cênica de Peter Hall}

Enquanto a escritura do libreto e a composição da partitura geralmente são criações individuais, a concretização cênica de uma ópera é uma arte coletiva. Na montagem de uma ópera, além do discurso sincrético, constituído pela fusão de palavras e música, outras especificidades do teatro contribuem para a composição da cena, como o trabalho de expressão facial e corporal dos atores, o cenário, a iluminação e outros recursos audiovisuais que interferem na gênese da criação artística. Trata-se de um processo transformacional intermidiático, no qual os componentes visuais, auditivos, ges- 
tuais e corporais, mencionados acima, são convertidos em situações concretas constitutivas da narrativa operística. Cumpre ressaltar, ainda, que as convicções individuais sobre a criação do espetáculo operístico variam de uma montagem para outra, visto que todo régisseur é, antes de tudo, um leitor que irá imprimir sua ótica particular ao espetáculo que será levado ao palco (HUTCHEON, 2017).

No início da década de 1980, Peter Hall assumiu a direção da performance dramática da ópera de câmara de Britten, em Glyndebourne. Esta encenação antológica foi reeditada nove vezes desde a estreia em 1981: a reedição mais recente foi em Glyndebourne em 2016, ano da celebração do aniversário de morte de Shakespeare.

No entanto, a admiração de Hall pela peça shakespeariana começou muito antes com a sua produção cênica do Sonho em Stratford-upon-Avon em 1959; esta montagem foi modificada e reapresentada em Stratford, em 1962 e, após novas mudanças, foi relançada no Teatro Aldwych, em Londres, em 1963. Hall voltou ao Sonho em 1999 com uma produção cênica no Ahmanson Theatre, em Los Angeles, e em 2010 reapresentou a produção com pequenas alterações no Rose Theatre, em Kingston-uponThames. As produções cênicas do Sonho formaram a base do filme rodado em 1967 e lançado em 1969 (WARREN, 2012).

Segundo Hall, o conhecimento adquirido ao longo de mais de cinquenta anos foi de grande valia para o projeto de encenação da ópera Sonho de Britten. Entre os elementos compositivos do espetáculo operístico, dirigido por Hall em $1981^{8}$, destaca-se o canto coral das fadas e elfos do séquito de Tytania (adaptado a partir de falas entre a Fada e Puck no início do segundo ato do texto de Shakespeare) executado pelo coro dos meninos sopranos da Trinity School (Trinity Boy Choir) em Croyden, os quais representam os seres elementais da floresta. Os figurinos dos meninos são elisabetanizados, constituídos de calção e gibão e golas elisabetanas. Esta cena inicial é inteiramente coreografada, e nos remete às companhias de atoresmirins (singing boy actors) do tempo de Shakespeare.

\footnotetext{
${ }^{8}$ No presente ensaio, a produção de Hall de 1981, em versão filmada disponível em DVD, foi utilizada como fonte de pesquisa para discutir algumas especificidades da cena operística.
} 
A floresta escura ao luar atrai e seduz por ser é uma entidade viva. Assim, torna-se palco e personagem do universo onírico na noite do solstício de verão, na qual fadas, amantes e artesãos se misturam e se relacionam. A música de Britten, que evoca o farfalhar da brisa, agitando as folhas das árvores e arbustos, foi traduzida por Hall em formas humanas que sussurram e dançam. Para tanto, o cenário é manipulado por atores caracterizados de árvores, os quais oferecem um balé contrapontístico ao canto dos intérpretes. John Bury, responsável pela cenografia e figurinos, enriqueceu a movimentação cênica com truques e armadilhas: Puck voa entre os galhos frondosos das árvores e Titania e sua corte desaparecem e reaparecem no negrume prateado da misteriosa floresta humanizada, a qual remete ao universo fantástico de Tolkien.

E, para a criação da materialidade cênica do universo das fadas, Hall recorre às artes plásticas, objetivando traduzir em termos visuais a atmosfera de sonho, fantasia e magia da floresta. Ao explorar a picturalidade como linguagem analógica e metafórica, opta pela transformação do real por conta do imaginário e pela recusa de levar em conta a dicotomia real versus sonho.

\section{Considerações finais}

A apropriação e adaptação das obras de Shakespeare em outras mídias é contínua, não como uma manifestação de nostalgia de uma época, mas como resposta às questões dos tempos contemporâneos (SANDERS, 2007). A ópera Sonho de uma noite de verão, de Britten, é uma obra-prima do gênero que mantém o mesmo sabor de novidade e criatividade desde a época de sua incepção, e o espetáculo operístico homônimo de Peter Hall, reeditado nove vezes ao longo de seus 35 anos de história, prossegue como inspiração e modelo de diferentes encenações ao redor do mundo.

A peça de Shakespeare, utilizada por Britten como texto-fonte, na qual se mesclam elementos díspares da alta cultura e da cultura popular, é um produto essencialmente híbrido, cuja força reside na interseção dos antigos polos dualistas que hoje são vistos como permeáveis e interpenetráveis. Essa hibridização atinge um grau de complexidade ainda maior na ópera de Britten e no espetáculo operístico dirigido por Hall. 
Na adaptação do Sonho de Shakespeare, Britten optou por interfaces e cruzamentos complexos e arrojados: os protocolos tradicionais da ópera italiana foram subvertidos por meio da mistura e fusão de múltiplas linguagens. Por outro lado, a concretização cênica de Hall resultou em uma síntese criativa que enriqueceu e revitalizou não somente a proposta operística de Britten, mas também a dramaturgia de Shakespeare.

\section{Referências}

BRITTEN, B. A New Britten Opera. In: A Midsummer Night's Dream. Overture Opera Guides. Richmond: Overture Publishing, 2011, p. 55-58.

A Midsummer Night's Dream. Glyndebourne Festival Opera, 1981. Direção: Peter Hall. Regência: Bernard Haitnik. DVD, color., 156 minutos.

A Midsummer Night's Dream. Overture Opera Guides. Richmond: Overture Publishing, 2011.

BROOKS, H. F. Introduction: Lyricism, Music and Dance. In: SHAKESPEARE, W. A Midsummer Night's Dream. The Arden Shakespeare. Ed. Harold F. Brooks. London: Thomson Learning, 2003, p. cxxcXXV.

CHAPPLE, F.; KATTENBELT, C. (Eds). Intermediality in Theatre and Performance. Amsterdam and New York: Rodopi, 2006.

CHAPPLE, F. Digital Opera: Intermediality, Remediation and Education. In: CHAPPLE, F.; KATTENBELT, C. (Eds). Intermediality in Theatre and Performance. Amsterdam and New York: Rodopi, 2006, p. 81-100.

CLÜVER, C. Inter textus/ Inter artes / Inter media. Tradução do alemão de Elcio Loureiro Cornelsen. AletriA: Revista de Estudos de Literatura - Intermidialidade, v.14, p.11-41, p. 11-41, jul./dez. 2006.

COLI, J. A paixão segundo a ópera. São Paulo: Perspectiva; FAPESP, 2003. HUTCHEON, L. Uma teoria da adaptação. Trad. André Cechinel. Florianópolis: Editora da UFSC, 2011.

HUTCHEON, L.; HUTCHEON, M. Adaptation and Opera. In: LEITCH, T. (Ed.). The Oxford Handbook of Adaptation Studies. Oxford and New York: Oxford University Press, 2017, p. 305-323.

LEITCH, T. (Ed.). The Oxford Handbook of Adaptation Studies. Oxford and New York: Oxford University Press, 2017.

PAVIS, P. A análise dos espetáculos. São Paulo: Perspectiva, 2003.

PICON-VALLIN, B. A cena em ensaios. Trad. Fátima Saadi, Cláudia Fares e Eloisa Araújo Ribeiro. São Paulo: Perspectiva, 2008. 
PLANT, A. Night's Caressing Dream: The Evolution of the Dream. In: BRITTEN, B. A Midsummer Night's Dream: Overture Opera Guides. Richmond: Overture Publishing, 2011, p. 9-21.

SANDERS, J. Giuseppe Verdi and Benjamin Britten: Case Studies in Shakespearean Opera. In: Shakespeare and Music: Afterlives and Borrowings. Cambridge UK and Malden USA: Polity Press, 2007, p. 112-134.

Shakespeare and Music: Afterlives and Borrowings. Cambridge UK and Malden USA: Polity Press, 2007.

SHAKESPEARE, W. A Midsummer Night's Dream. The Arden Shakespeare. Ed. Harold F. Brooks. London: Thomson Learning, 2003.

WARREN, R. Staging a Midsummer Night's Dream: Peter Hall's Productions, 1959-2010. Shakespeare Survey, v. 65, 2012, p. 147-154.

\section{Resumo}

Situada na interface do teatro, da música e das artes visuais, a ópera encenada é constituída pela fusão de linguagens. Este ensaio reflete sobre Sonho de uma noite de verão (1960), ópera de câmara de Benjamin Britten (19131976), composta a partir do texto homônimo de Shakespeare, e analisa a adaptação cênica apresentada em Glyndebourne (1981), dirigida por Peter Hall (1930-2017). Os diálogos intermidiáticos entre Shakespeare, Britten e Hall serão investigados à luz de considerações teóricas de Linda e Michael Hutcheon, Claus Clüver, Jorge Coli, Freda Chapple e outros.

Palavras-chave: Adaptação; transposição midiática; combinação de mídias; referências intermidiáticas.

\footnotetext{
Abstract

Opera productions, located at the intersection of theater, music and the visual arts, tend to fuse multiple languages. This essay reflects on the chamber opera A Midsummer Night's Dream (1960), composed by Benjamin Britten (1913-1976) based on Shakespeare's homonymous text, and analyses the 1981 stage adaptation at Glyndebourne, directed by Peter Hall (19302017). The intermedial dialogues among Shakespeare, Britten and Hall will be investigated in the light of theoretical perspectives by Linda and Michael Hutcheon, Claus Clüver, Jorge Coli, Freda Chapple and others.
} 
CAMATI Sonho de uma noite de verão: de Shakespeare a Britten

Keywords: Adaptation; media transposition; media combination; intermedial references. 